\title{
Behavior of HSI Color Co-Occurrence Features in Variety Recognition from Bulk Paddy Grain Image Samples
}

\author{
Basavaraj S. Anami ${ }^{1}$, Naveen N. M. ${ }^{2}$ and N. G. Hanamaratti ${ }^{3}$ \\ ${ }^{1}$ Department of Computer Science and Engineering, $K L$ E Institute of \\ Technology, Hubli, 580030, India \\ ${ }^{2}$ Department of Information Science and Engineering, $K L$ E Institute of \\ Technology, Hubli, 580030, India \\ ${ }^{3}$ Department of Genetics and Plant Breeding, University of Agricultural Sciences, \\ Dharwar, 580002, India \\ anami_basu@hotmail.com,naveen.malvade@gmail.com, \\ hanamaratti@gmail.com
}

\begin{abstract}
Computer vision applications in the field of agriculture science are gaining importance. The paper presents a method for recognition of paddy varieties from bulk paddy grain image samples based on color texture features extracted from color cooccurrence matrices. The color texture features are obtained from $\mathrm{H}, \mathrm{S}$ and I color planes and their combinations. The feature set is reduced based on contribution of features to the recognition accuracy. The reduced feature set of the HS plane includes Energy, Entropy and Correlation features from Hue plane and Energy, Entropy, Contrast, and Correlation features from Saturation plane. The paddy grain images are recognized using a multilayer feed-forward artificial neural network. The considered fifteen paddy varieties have given the recognition accuracy of 92.33\%. The work is useful in developing a machine vision system for agriculture produce market and developing multimedia applications in agriculture sciences.
\end{abstract}

Keywords: Paddy, Color texture features, Feature extraction, ANN, Pattern recognition

\section{Introduction}

India is an agriculture based country which decides its economy. Agriculture sector contributes around 26 percent of the gross domestic product (GDP). Paddy, Jowar, Wheat, Sugarcane, Maize are few major crops in different parts of India. Paddy is one of the most important universal cereal grain crop and it is grown in all the continents except Antarctica. India is the second largest producer of wheat and paddy. India and China are competing to establish the world record on rice yields. Its cultivation is of immense importance to food security of Asia, where more than $90 \%$ of the global rice is produced and consumed. Some paddy varieties cultivated in Karnataka, India are given in Figure 1.

Human beings recognize the paddy varieties during quality evaluation and cultivation. The grain quality, yield, resistance to pests and diseases, tolerance to environmental stresses, farm input requirement, the production of rice, rice flakes and puffed rice and pricing, all these depend upon the variety. At present paddy grain handling operation is carried out manually (also referred to as visual inspection) by the trained personnel and is considered as time consuming and moreover subjective. These shortcomings of manual approach demand for the development of a machine vision system to automatically carry out recognition of paddy variety. This automation would benefit the potential farmers in getting their right price and right variety for cultivation. In order to know the state-of-the- 
art in automation of such activities in the field of agriculture, we have carried out a survey and the gist of papers given under is divided into two broad categories, one paddy related and the other allied.

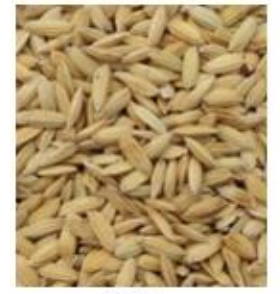

(a)

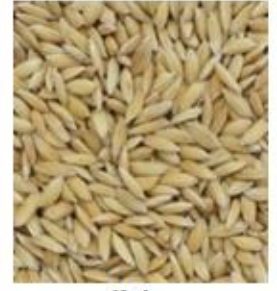

(b)

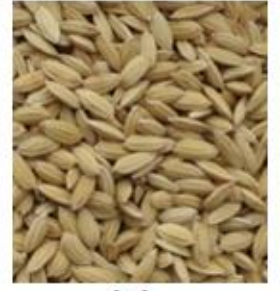

(c)

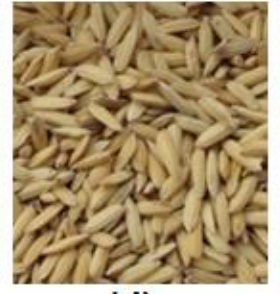

(d)

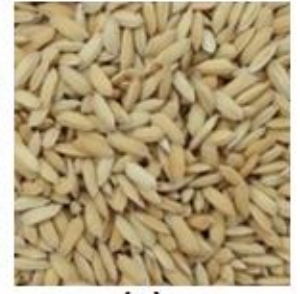

(e)

Figure 1. Some Leading Paddy Varieties in Karnataka State, India (a) Abhilasha (b) Bhagyajyothi (c) Budda (d) Intan (e) Jaya

(Mousavi Rad, et al., 2014) presented an algorithm to classify five different varieties of rice from unshelled singleton kernel using the color and texture features. The method used a feed-forward neural network classifier for recognition of rice varieties and obtained 96.67\% accuracy. (Golpour I., et al., 2014) proposed an image processing algorithm for classification of bulk paddy, brown and white variety using 36 color features in RGB, HIS and HSV color spaces. The algorithm adopted backpropagation neural network for classification and obtained a mean classification accuracy of $96.66 \%$ with 13 color features. (Pazoki A. R., et al., 2014) proposed a methodology for the classification of 5 paddy grain varieties using 24 color features, 11 morphological features and 4 shape features. The features extracted from color images of singleton grains of paddy gave classification accuracies of $99.46 \%$ and $99.73 \%$ for multi layer perceptron (MLP) and neuro-fuzzy classifiers respectively. (Archana, et al., 2014), proposed an algorithm to classify four paddy varieties from shape and texture features using artificial neural network. The algorithm gave accuracies of $82.61 \%, 88.00 \%$, and $87.27 \%$ for texture, shape and texture and shape features respectively. The algorithm used singleton paddy grain images. (Mousavi Rad, et al., 2012) presented image processing techniques to identify five different classes of unshelled rice varieties using ensemble classifier. The forty-one morphological features used to train ANN classifier gave $99.86 \%$ recognition accuracy. (Pourreza, et al., 2012) applied machine vision techniques for the classification of wheat varieties using one hundred and thirty one texture features. The features included were GLCM (gray level co-occurrence matrix), GLRM (gray level run-length matrix), LBP (local binary patterns), LSP (local similarity patterns) and LSN (local similarity numbers). The deployed LDA (linear discriminate analysis) classifier gave an average classification accuracy of $98.15 \%$. The results revealed that LSP, LSN and LBP features had significant influence on classification accuracy. (Guzman J. D., et al., 2008) proposed a machine vision system based on neural networks for automatic identification of five paddy varieties of Philippines based on morphological features. The method gave a classification accuracy of 70\%.

(Savakar D. G. 2010) illustrated an algorithm for recognition and classification of similar looking grain images using backpropagation artificial neural network. The method gave accuracy in the range $78-84 \%$ for individual color and texture features and in the range $85-90 \%$ for combined color and texture features. (Anami B. S., et al., 2009) presented a methodology to identify the different grain types from image samples of tray containing multiple grains using color and textural features. A backpropagation neural network was used for identification of bulk food grains using eighteen color and texture features. Five different types of grains namely, alasandi, green gram, metagi, red gram and wheat were tested and identification accuracies observed in this work were $94 \%$ and $80 \%$ for wheat and alasandi. (Anami B. S., et al., 2005) developed a Neural network 
approach for classification of single grain kernels of different grains like wheat, maize, groundnut, redgram, greengram and blackgram based on color, area covered, height and width. The minimum and maximum classification accuracies reported were $80 \%$ and $90 \%$ respectively. (Anami B. S., et al., 2009) presented different methodologies devised for recognition and classification of images of agricultural/horticultural produce based on BPNN using color, texture and morphological features with $87.5 \%$ accuracy. (Huang, et al., 2004) proposed an identification method based on Bayes' decision theory to classify rice variety from individual grain samples using color and shape features with $88.3 \%$ accuracy. (Visen, et al., 2004) proposed combined color and texture features based methodology to identify grain type from color images of bulk grains using backpropagation neural network. A feature set consisting of 154 features was reduced to 20. Classification accuracies of over $98 \%$ were obtained for five grain types, namely barley, oats, rye, wheat, and durum wheat for combined ten color features and ten texture features, (Paliwal, et al., 2004) proposed a robust algorithm for classifying images of bulk samples of barley, wheat, oats, and rye using a four layer back propagation neural network and obtained classification accuracy of $99 \%$ using combined color and texture features. (S. A. Shearer and R. G. Holmes, 1990) proposed a method for identifying plants based on color texture characterization of canopy sections. Color co-occurrence matrices were derived from images, one for each color attribute: intensity, saturation, and hue giving 11 texture features. The LDA with 33 color texture features were used to identify plants. Overall classification accuracy of $91 \%$ was obtained.

From the literature survey, it is observed that there is some amount of research carried related to recognition and classification of paddy grains and rice kernels. The published work has mainly focused on classification of paddy grains in singleton and non-touching grains. The number of varieties is small. The morphological, color, texture and shape features are employed in the works. The size of the feature set adopted is large and amounts to increased computational overhead during classification of bulk paddy grains. Further, limited work is noticed on variety identification from bulk samples of paddy grains. This is the motivation for the present work, with an aim to devise a smaller feature set, based on color texture features, for variety recognition from bulk paddy grain sample images.

\section{Proposed Method}

The proposed method consists of four stages, namely, image acquisition, feature extraction, feature selection and variety recognition as shown in Figure 2. The bulk images of 15 paddy grain varieties and texture features in HSI color space are considered. A multilayer feed-forward artificial neural network is used as recognizer of paddy varieties.

\subsection{Image Acquisition}

In consultation with the University of Agricultural Sciences (UAS), Dharwad, Karnataka State, India, fifteen certified and popular paddy varieties are selected as grain samples in the work. The paddy varieties are obtained from Agricultural Research Station, Mugad, Dharwad. These varieties are grown in different parts of Karnataka, India. The varieties considered in the work include, Abhilasha, Bhagyajyothi, Budda, Intan, Jaya, Jayashree, Mugad Dodiga, Mugad Sughand, Mugad 101, Mugad Siri, PSB 68, Rajakaima, Redjyothi, Thousand One and Thousand Ten. The paddy varieties are shown in Figure 1 and Figure 3.

A total 3000 images, considering 200 images from each type of 15 paddy varieties are acquired under standard lighting conditions using color camera PENTAX MX-1, USA, having resolution of 14 mega pixels. In order to provide a stable support and easy vertical movement, the camera is mounted on a tripod stand as shown in Figure 4. The images are 
taken keeping approximately the object distance of $0.5 \mathrm{~m}$. The acquired images of size $1920 \times 1080$ pixels are resized to $400 \times 400$ pixels for the reasons of reduction in computational overhead and storage requirements.

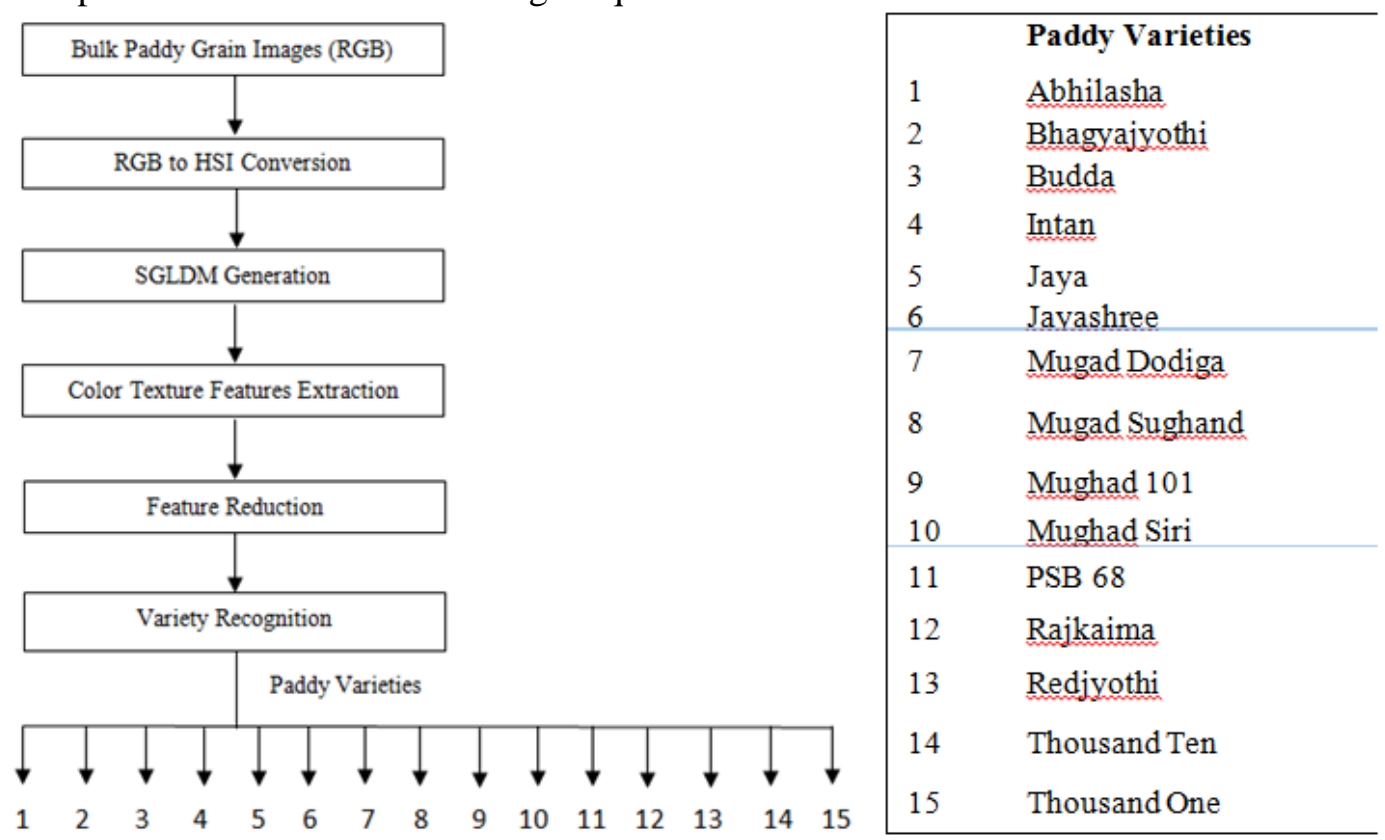

Figure 2. Block Diagram of the Proposed Method

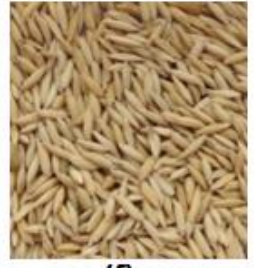

(f)

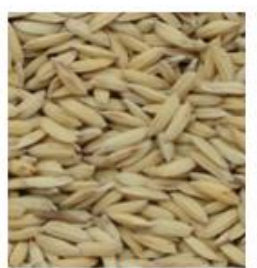

(k)

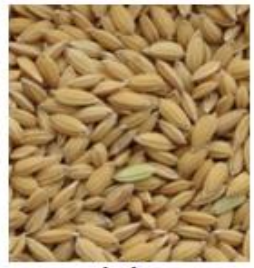

(g)

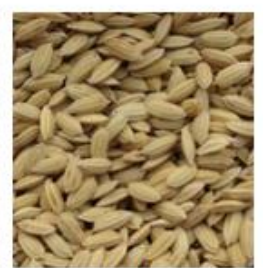

(I)

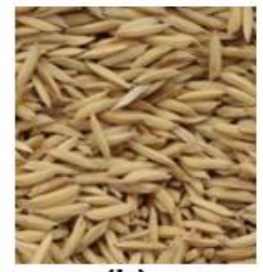

(h)

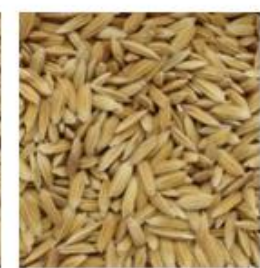

(m)

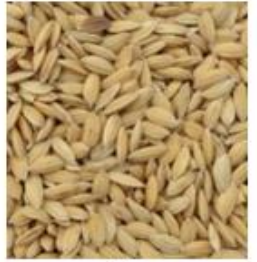

(i)

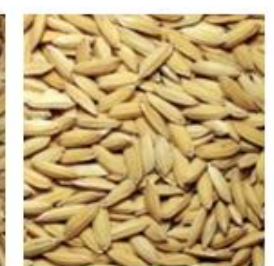

(n)

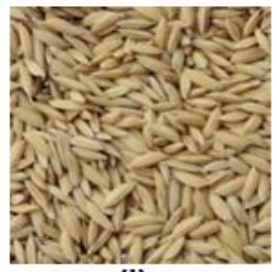

(j)

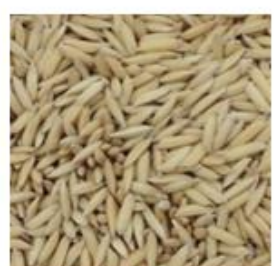

(o)

Figure 3. Images of Paddy Varieties ( $f$ ) Jayashree (g) Mugad Dodiga (h) Mugad Sughand (i) Mugad 101 (j) Mugad Siri (k) PSB 68 (I) Rajakaima (m) Redjyothi (n) Thousand One (o) Thousand Ten

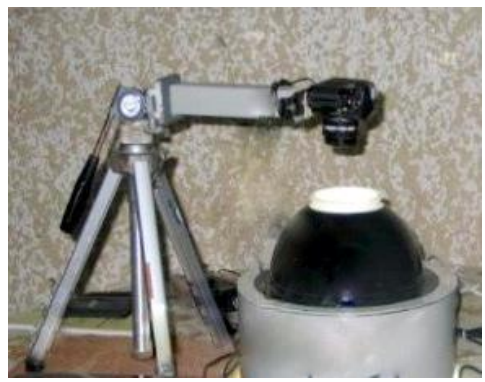

Figure 4. Image Acquisition Setup 


\subsection{Feature Extraction}

The paddy varieties are, more or less, of the same color with varying shades. The bulk paddy samples exhibit color texture features [16]. This is the reason for adopting color texture features from color co-occurrence matrix (CCM) in the work, which is given in Algorithm 1. We have adopted HSI color model. Each of the three Spatial Gray Level Dependence Matrices (SGDM's) are considered giving 13 texture features for each component of HSI resulting in a total of 39 texture features [15]. The experiments are conducted with each of the HSI color planes and texture features to determine the recognition accuracy. Only 5 texture features, namely, Energy, Entropy, Homogeneity, Contrast and Correlation are found to be significant in each of $\mathrm{H}, \mathrm{S}$ and I plane in classifying paddy varieties. Thus, a total of 15 texture features are used. These features are extracted using the Equations (4) thru (8). The texture feature values for all the paddy varieties are given in Table 1.

Algorithm 1: Color texture features extraction using color co-occurrence matrix method. Input: Bulk paddy grains RGB image.

Output: Color texture features

Start

Step 1: Transform RGB color model to HSI color model, using equations (1) thru

Step 2: Obtain color co-occurrence matrix for each $\mathrm{H}, \mathrm{S}$ and I planes.

Step 3: Obtain SGLDM for each color co-occurrence matrix generated in Step 2. Step 4: Perform texture statistics computation using GLCM.

End

$$
\begin{aligned}
& H=\cos ^{-1}\left(\frac{\frac{1}{2}[(R-G)+(R-B)]}{\left[(R-G)^{2}+(R-B)(G-B)\right]^{\frac{1}{2}}}\right) \\
& S=1-\frac{3}{(R+G+B)}[\min (R, \quad G, B)]
\end{aligned}
$$

$\mathrm{I}=\frac{1}{3}(\mathrm{R}+\mathrm{G}+\mathrm{B})$

$$
\text { Energy } \quad=\sum_{\mathrm{i}=0}^{\mathrm{N}_{\mathrm{g}}-1} \sum_{\mathrm{j}=0}^{\mathrm{N}_{\mathrm{g}}-1} \mathrm{P}(\mathrm{i}, \mathrm{j})^{2}
$$

$$
\text { Entropy } \quad=\sum_{i=0}^{N_{i}-1} \sum_{j=0}^{N_{s}-1} P(i, j) \log P(i, j)
$$

$$
\text { Homogeneity }=\sum_{i=0}^{N_{-}-1} \sum_{j=0}^{N_{g}-1} \frac{P(i, j)}{1+(i-j)^{2}}
$$

$$
\text { Contrast } \quad=\sum_{|i-j|=0}^{N_{g}-1}(i-j)^{2} \sum_{i=0}^{N_{g^{2}}-1} \sum_{j=0}^{N_{g}-1} P(i, j)
$$

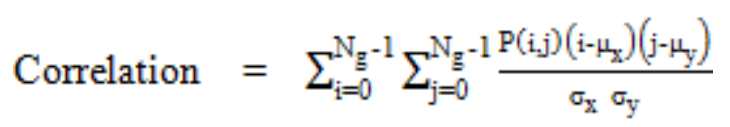

Here, $P(i, j)$ represents the image attribute matrix, $P(i, j, 1,0)$ represents the intensity co-occurrence matrix, $\mathrm{Ng}$ (total number of grey levels) $=256, \mu_{x}, \mu_{y}$ and $\sigma_{x}, \sigma_{y}$ denote 
the mean and standard deviations of the row and column sums of the matrix respectively (related to the marginal distributions $P_{x}(i)$ and $P_{y}(j)$ ).

Table 1. Texture Feature Values from $\mathrm{H}, \mathrm{S}$ and I Color Planes

\begin{tabular}{|c|c|c|c|c|c|c|c|c|c|c|c|c|c|c|c|c|}
\hline \multirow[b]{2}{*}{ Sl. No. } & \multirow[b]{2}{*}{ Paddy Variety } & \multicolumn{5}{|c|}{ Hue Plane } & \multicolumn{5}{|c|}{ Saturation Plane } & \multicolumn{5}{|c|}{ Intensity Plane } \\
\hline & & 起 & $\stackrel{\vec{a}}{\frac{a}{g}}$ & 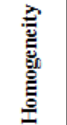 & $\begin{array}{l}\vec{y} \\
\text { है } \\
\text { है }\end{array}$ & $\frac{\tilde{g}}{\mathrm{E}}$ & 悹 & $\stackrel{\overrightarrow{\mathrm{g}}}{\mathrm{g}}$ & 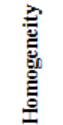 & $\begin{array}{l}\vec{y} \\
\text { है } \\
\text { है }\end{array}$ & 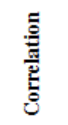 & 豞 & 商 & 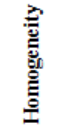 & 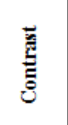 & 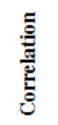 \\
\hline 1 & bhi & 0.999 & 0.518 & 0.999 & 0.088 & 0.183 & 0.439 & 1.438 & 0.947 & 0.840 & .778 & 699 & 0.876 & 0.972 & 0.441 & 0.979 \\
\hline 2 & Bhagyajyothi & 0.998 & 0.785 & 0.999 & 0.090 & 0.239 & 0.523 & 1.262 & 0.954 & 0.698 & 0.769 & 0.722 & 0.826 & 0.973 & 0.399 & 0.980 \\
\hline 3 & Budda & 0.999 & 0.701 & 0.999 & 0.069 & 0.198 & 0.457 & 1.365 & 0.956 & 0.840 & 0.813 & 0.579 & 1.109 & 0.969 & 0.663 & 0.977 \\
\hline 4 & Intan & 0.998 & 0.895 & 0.999 & 0.090 & 0.173 & 0.435 & 1.428 & 0.949 & 0.849 & 0.788 & 0.580 & 1.135 & 0.961 & 0.621 & 0.969 \\
\hline 5 & $\mathrm{Ja}$ & 0.999 & 0.601 & 0. & 0. & 0.21 & 0. & 1.020 & 0.966 & 0.542 & 0.781 & 26 & 10 & 0.975 & 0.403 & 0.983 \\
\hline 6 & Laydsutere & 0.825 & 2.412 & 0.994 & 0.510 & 0.541 & 0.500 & 1.318 & 0.949 & 0.717 & 0.753 & 0.726 & 0.832 & 0.968 & 0.363 & 0.975 \\
\hline 7 & Mugad Dodiga & 0.819 & 0.702 & 0.989 & 0.066 & 0.167 & 0.420 & 1.438 & 0.953 & 0.898 & 0.812 & 0.616 & 1.041 & 0.970 & 0.594 & 0.978 \\
\hline 8 & Mugad Sughand & 0.698 & 0.740 & 0.999 & 0.075 & 0.210 & 0.434 & 1.388 & 0.960 & 0.904 & 0.837 & 0.619 & 1.023 & 0.972 & 0.603 & 0.981 \\
\hline 9 & Mughad 101 & 0.659 & 0.337 & 0.997 & 0.033 & 0.124 & 0.424 & 1.456 & 0.946 & 0.85 & 0.777 & 0.680 & 0.915 & 0.971 & 0.473 & 0.979 \\
\hline 10 & Mughad Siri & 0.788 & 0.788 & 0.899 & 0.078 & 0.186 & 0.475 & 1.342 & 0.955 & 0.795 & 0.796 & 0.592 & 1.102 & 0.965 & 0.615 & 0.973 \\
\hline 11 & PSB 68 & 0.798 & 0.721 & 0.999 & 0.090 & 0.317 & 0.644 & 0.988 & 0.970 & 0.540 & 0.801 & 0.681 & 0.898 & 0.975 & 0.493 & 0.983 \\
\hline 12 & Rajkaima & 0.788 & 1.238 & 0.699 & 0.219 & 0.307 & 0.518 & 1.258 & 0.956 & 0.719 & 0.782 & 0.689 & 0.894 & 0.971 & 0.454 & 0.978 \\
\hline 13 & Redjyothi & 0.908 & 1.141 & 0.817 & 0.146 & 0.268 & 0.384 & 1.578 & 0.929 & 0.846 & 0.713 & 0.680 & 0.934 & 0.965 & 0.441 & 0.972 \\
\hline 14 & Thousand Ten & 0.928 & 0.725 & 0.799 & 0.090 & 0.258 & 0.680 & 0.926 & 0.967 & 0.454 & 0.749 & 0.718 & 0.834 & 0.972 & 0.405 & 0.980 \\
\hline 15 & Thousand One & 0.938 & 0.754 & 0.899 & 0.093 & 0.218 & 0.486 & 1.312 & 0.957 & 0.785 & 0.801 & 0.646 & 0.979 & 0.970 & 0.539 & 0.979 \\
\hline
\end{tabular}

\subsection{Feature Selection}

In order to reduce the computational overhead, the feature set is reduced. The useful features that contribute to the recognition process are selected by testing for recognition each individual texture feature. We have selected through experimentation, a minimum of 5 texture features for each of the color planes and a total of 15 features are selected. The features selection process is given in Algorithm 2.

Algorithm 2: Selection of color texture features based on recognition accuracy.

Input: Extracted color texture features along with the average recognition accuracies

(ARA) of all the features.

Output: Reduced feature sets with selected features.

Start

Step 1: Find out minimum and maximum average recognition accuracies in all the color texture features.

$\mathrm{X}=\mathrm{MINIMUM}(\mathrm{ARA}) / /$ Minimum average recognition accuracy in all the color texture features

$\mathrm{Y}=$ MAXIMUM(ARA) // Maximum average recognition accuracy in all the color texture features

Step 2: Compute recognition accuracy threshold (RAT) value.

$\mathrm{RAT}=(\mathrm{X}+\mathrm{Y}) / 2$

Step 3: Compare the average recognition accuracies of all the features with RAT.

Construct reduced feature set by selecting the color texture features whose average recognition accuracies are equal to or greater than the RAT value.

Step 4: Compare, if RAT $<=\mathrm{Y}$, then $\mathrm{X}=\mathrm{RAT}$ and go to Step 2 else return the reduced feature sets.

End 


\subsection{Recognition of Paddy Varieties}

A multilayer feed-forward neural network is considered for paddy variety recognition. The number of neurons in the input layer is set to the number of appropriate texture features selected as input and the output layer is set to 15. Levenberg-Marquardt (LM) backpropagation algorithm is used for the training. The termination error (TE) is set to 0.01 , learning rate $(\eta)$ is set to 0.05 and momentum coefficient $(\mu)$ is set to 0.6. The sigmoid activation functions are used in the hidden layers. The network is trained and tested for 2000 epochs. With these parameters, the network is trained. Once the training is complete, the test data for each of the paddy variety is tested. The overall recognition process is given in Algorithm 3.

Algorithm 3: Overall recognition of paddy varieties from bulk grain sample images using color texture features.

Input: Bulk paddy sample images of different varieties.

Output: Recognized paddy variety

Start

Step 1: Extract color texture features of the input images using Algorithm 1.

Step 2: Perform feature selection using Algorithm 2

Step 3: Train artificial neural network (ANN) with the selected color texture feature set obtained in Step 2.

Step 4: Accept test image and extract the selected color texture features using Algorithm 1.

Step 5: Recognize the image containing bulk paddy sample using ANN classifier.

Repeat the steps 4 and 5 for all the test images.

End

\section{Results and Discussion}

The software tool MATLAB 7.11.0 is used to implement the devised algorithms. A total of 3000 image samples, 200 images of each varietal type are considered. Out of these image samples 1500 images (100 images of each paddy variety) are used for training and 1500 images (100 images of each paddy variety) are used for testing. The percentage of recognition accuracy is defined as the ratio of correctly recognized image samples to the total number of test image samples as given by Equation 9 .

Avg. Recognition Accuracy $(\%)=\frac{\text { Correctly recognized image samples }}{\text { Total number of test image samples }} \times 100$

\subsection{Recognition Using Color Texture Features}

The training and testing processes are carried out using color texture features, five significant color texture features, in $\mathrm{H}, \mathrm{S}$ and I color planes. The individual color planes and their combinations, namely, HI, HS and SI are considered for experimentation. The results of the experiments are given in Table 2. The observed maximum and minimum average accuracies are $59.13 \%$ and $46.33 \%$ for individual Hue $(\mathrm{H})$ and Intensity (I) planes respectively. The maximum and minimum average recognition accuracies (ARA) of 86.93\% and $74.20 \%$ are observed for the combinations HS and HI planes respectively.

Table 2. Recognition Results for Color Texture Features of Individual and Combined $\mathrm{H}$, S and I Planes

\begin{tabular}{|c|c|c|}
\hline SI. & Paddy Variety & Individual / Combined H, S and I planes \\
\hline
\end{tabular}




\begin{tabular}{|c|l|c|c|c|c|c|c|c|} 
No & & H & S & I & HS & HI & SI & HSI \\
\hline 1 & Abhilasha & 65 & 44 & 55 & 89 & 66 & 71 & 78 \\
\hline 2 & Bhagyajyothi & 62 & 48 & 52 & 85 & 72 & 88 & 67 \\
\hline 3 & Budda & 73 & 38 & 34 & 95 & 78 & 62 & 85 \\
\hline 4 & Intan & 46 & 42 & 48 & 92 & 82 & 75 & 73 \\
\hline 5 & Jaya & 61 & 41 & 32 & 90 & 69 & 77 & 72 \\
\hline 6 & Jayashree & 56 & 34 & 39 & 82 & 87 & 79 & 69 \\
\hline 7 & Mugad Dodiga & 62 & 47 & 41 & 88 & 73 & 72 & 74 \\
\hline 8 & Mugad Sughand & 55 & 32 & 44 & 79 & 72 & 69 & 88 \\
\hline 9 & Mughad 101 & 61 & 66 & 47 & 83 & 69 & 75 & 91 \\
\hline 10 & Mughad Siri & 45 & 59 & 48 & 84 & 70 & 88 & 68 \\
\hline 11 & PSB 68 & 59 & 66 & 42 & 85 & 73 & 83 & 89 \\
\hline 12 & Rajkaima & 61 & 59 & 43 & 93 & 75 & 73 & 91 \\
\hline 13 & Redjyothi & 62 & 44 & 49 & 79 & 69 & 70 & 84 \\
\hline 14 & Thousand One & 59 & 43 & 55 & 87 & 78 & 66 & 85 \\
\hline 15 & Thousand Ten & 60 & 63 & 66 & 93 & 80 & 91 & 76 \\
\hline \multicolumn{2}{|c|}{ ARA $(\mathbf{\%})$} & $\mathbf{5 9 . 1 3}$ & $\mathbf{4 8 . 4 1}$ & $\mathbf{4 6 . 3 3}$ & $\mathbf{8 6 . 9 3}$ & $\mathbf{7 4 . 2}$ & $\mathbf{7 5 . 9 3}$ & $\mathbf{7 9 . 3 3}$ \\
\hline
\end{tabular}

\subsection{Recognition Using Reduced Color Texture Features}

The feature reduction process is performed to improve the average recognition accuracy of the combined HS plane texture features using Algorithm 2. The individual color texture feature contribution to the recognition accuracy is evaluated in selecting a feature in the feature set and results are shown in Table 3 . The color texture features are reduced to obtain feature sets for the HS planes using Algorithm 2 and Table 4 gives the details of reduced feature sets.

Five reduced color texture feature sets are obtained for the combined HS color plane, are given in Table 4. All these reduced feature sets are used to train and test ANN and the results of the same are given in Table 5. The plot of reduced feature set sizes versus obtained average recognition accuracies is given in Figure 5. The overall behavior of HSI color co-occurrence texture features for recognition of bulk samples of paddy varieties is shown in Figure 6. The reduced HS plane texture features have given the highest recognition accuracy of $92.33 \%$ than other combination of texture features. The reduced feature set of the HS plane includes Energy, Entropy and Correlation features from Hue plane and Energy, Entropy, Contrast, and Correlation features from Saturation plane.

The proposed method has considered fifteen paddy varieties, which is three times more than the reported work and the number of features considered is half of the features used in the reported work as depicted in Table 6.

\section{Table 3. Recognition Accuracies for Individual Texture Feature from} Combined HS Color Plane

\begin{tabular}{|c|c|c|c|c|c|c|c|c|c|c|c|}
\hline \multirow[b]{2}{*}{$\begin{array}{l}\text { Sl. } \\
\text { No. }\end{array}$} & \multirow[b]{2}{*}{ Paddy Variety } & \multicolumn{5}{|c|}{ Hue Plane } & \multicolumn{5}{|c|}{ Saturation Plane } \\
\hline & & 占 & 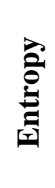 & 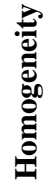 & $\begin{array}{l}\overrightarrow{\tilde{z}} \\
\stackrel{\vec{E}}{\tilde{E}} \\
\dot{0}\end{array}$ & 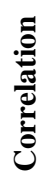 & 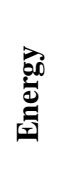 & 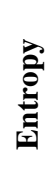 & 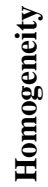 & $\begin{array}{l}\overrightarrow{\tilde{E}} \\
\overrightarrow{\tilde{E}}\end{array}$ & نี \\
\hline 1 & Abhilasha & 57 & 66 & 21 & 33 & 41 & 49 & 52 & 6 & 45 & 43 \\
\hline 2 & Bhagyajyothi & 49 & 69 & 26 & 31 & 45 & 57 & 53 & 10 & 51 & 43 \\
\hline 3 & Budda & 55 & 59 & 15 & 29 & 41 & 48 & 57 & 12 & 58 & 50 \\
\hline 4 & Intan & 61 & 71 & 19 & 26 & 47 & 50 & 59 & 15 & 51 & 44 \\
\hline 5 & Jaya & 45 & 63 & 23 & 38 & 51 & 54 & 51 & 11 & 67 & 47 \\
\hline 6 & Jayashree & 42 & 58 & 22 & 31 & 43 & 58 & 61 & 5 & 62 & 45 \\
\hline 7 & Mugad Dodiga & 48 & 55 & 11 & 45 & 46 & 56 & 48 & 8 & 63 & 44 \\
\hline 8 & Mugad & 57 & 57 & 13 & 35 & 44 & 52 & 47 & 4 & 55 & 46 \\
\hline
\end{tabular}




\begin{tabular}{|c|l|c|c|c|c|c|c|c|c|c|c|}
\multicolumn{1}{l|}{ Sughand } & & & & & & & & & & \\
\hline 9 & Mughad 101 & 51 & 49 & 16 & 45 & 46 & 57 & 45 & 11 & 49 & 51 \\
\hline 10 & Mughad Siri & 52 & 50 & 31 & 45 & 51 & 54 & 55 & 23 & 52 & 44 \\
\hline 11 & PSB 68 & 44 & 53 & 22 & 33 & 49 & 49 & 61 & 10 & 40 & 52 \\
\hline 12 & Rajkaima & 47 & 62 & 24 & 31 & 46 & 54 & 59 & 25 & 44 & 49 \\
\hline 13 & Redjyothi & 59 & 44 & 10 & 39 & 49 & 50 & 68 & 21 & 62 & 46 \\
\hline 14 & Thousand Ten & 66 & 52 & 16 & 37 & 47 & 55 & 49 & 19 & 39 & 45 \\
\hline 15 & Thousand One & 53 & 51 & 22 & 35 & 50 & 44 & 54 & 24 & 54 & 52 \\
\hline & & $\mathbf{5 7 . 2}$ & $\mathbf{1 9 . 4}$ & $\mathbf{3 5 . 5}$ & $\mathbf{4 6 . 4}$ & $\mathbf{5 2 . 4}$ & $\mathbf{5 4 . 6}$ & $\mathbf{1 3 . 6}$ & $\mathbf{5 2 . 8}$ & $\mathbf{4 6 . 7}$ \\
& ARA (\%) & $\mathbf{5 2 . 4 0}$ & $\mathbf{7}$ & $\mathbf{0}$ & $\mathbf{3}$ & $\mathbf{0}$ & $\mathbf{7}$ & $\mathbf{0}$ & $\mathbf{0}$ & $\mathbf{0}$ & $\mathbf{3}$ \\
\hline
\end{tabular}

Table 4. Reduced Feature Sets for Combined HS Color Plane Obtained from Algorithm 2

\begin{tabular}{|c|l|c|c|c|}
\hline $\begin{array}{c}\text { Recognition } \\
\text { Accuracy } \\
\text { Threshold } \\
\text { (RAT) }\end{array}$ & \multicolumn{1}{|c|}{ Reduced Feature Set } & $\begin{array}{c}\text { Reduced } \\
\text { Feature } \\
\text { Set Size }\end{array}$ & $\begin{array}{c}\text { Minimu } \\
\text { m ARA } \\
\text { (X) }\end{array}$ & $\begin{array}{c}\text { Maximu } \\
\text { m } \\
\text { ARA(Y) }\end{array}$ \\
\hline 35.44 & $\begin{array}{l}\text { Hue \{Energy, Entropy, Contrast, Correlation\} } \\
\text { Saturation \{Energy, Entropy, Contrast, } \\
\text { Correlation\} }\end{array}$ & 8 & 13.60 & 57.27 \\
\hline 46.35 & $\begin{array}{l}\text { Hue \{Energy, Entropy, Correlation\} } \\
\text { Saturation \{Energy, Entropy, Contrast, } \\
\text { Correlation\} }\end{array}$ & 7 & 35.44 & 57.27 \\
\hline 51.81 & $\begin{array}{l}\text { Hue }\{\text { Energy, Entropy\}, Saturation \{Energy, } \\
\text { Entropy\} }\end{array}$ & 4 & 46.35 & 57.27 \\
\hline 54.54 & Hue \{ Entropy\}, Saturation\{ Entropy & 2 & 51.81 & 57.27 \\
\hline 55.90 & Hue \{ Entropy\} & 1 & 54.54 & 57.27 \\
\hline
\end{tabular}

Table 5. Recognition Accuracies for Reduced Feature Sets of Combined HS Color Plane

\begin{tabular}{|c|l|c|c|c|c|c|}
\hline \multirow{2}{*}{$\begin{array}{c}\text { Sl. } \\
\text { No }\end{array}$} & \multicolumn{2}{|c|}{ Paddy Variety } & \multicolumn{5}{|c|}{ Reduced feature set size } \\
\cline { 3 - 7 } & & $\mathbf{8}$ & $\mathbf{7}$ & $\mathbf{4}$ & $\mathbf{2}$ & $\mathbf{1}$ \\
\hline 1 & Abhilasha & 93 & 94 & 82 & 71 & 66 \\
\hline 2 & Bhagyajyothi & 77 & 88 & 76 & 78 & 69 \\
\hline 3 & Budda & 89 & 93 & 90 & 81 & 59 \\
\hline 4 & Intan & 92 & 97 & 83 & 76 & 71 \\
\hline 5 & Jaya & 88 & 95 & 85 & 73 & 63 \\
\hline 6 & Jayashree & 79 & 89 & 90 & 77 & 58 \\
\hline 7 & Mugad Dodiga & 86 & 86 & 96 & 83 & 55 \\
\hline 8 & Mugad Sughand & 91 & 95 & 80 & 69 & 57 \\
\hline 9 & Mughad 101 & 93 & 95 & 93 & 71 & 49 \\
\hline 10 & Mughad Siri & 76 & 93 & 77 & 68 & 50 \\
\hline 11 & PSB 68 & 88 & 85 & 82 & 70 & 53 \\
\hline 12 & Rajkaima & 95 & 98 & 80 & 74 & 62 \\
\hline 13 & Redivothi & 98 & 98 & 83 & 63 & 44 \\
\hline 14 & Thousand One & 87 & 90 & 90 & 59 & 52 \\
\hline 15 & Thousand Ten & 83 & 89 & 79 & 78 & 51 \\
\hline & ARA (\%) & $\mathbf{8 7 . 6 7}$ & $\mathbf{9 2 . 3 3}$ & $\mathbf{8 4 . 4 0}$ & $\mathbf{7 2 . 7 3}$ & $\mathbf{5 7 . 2 7}$ \\
\hline
\end{tabular}




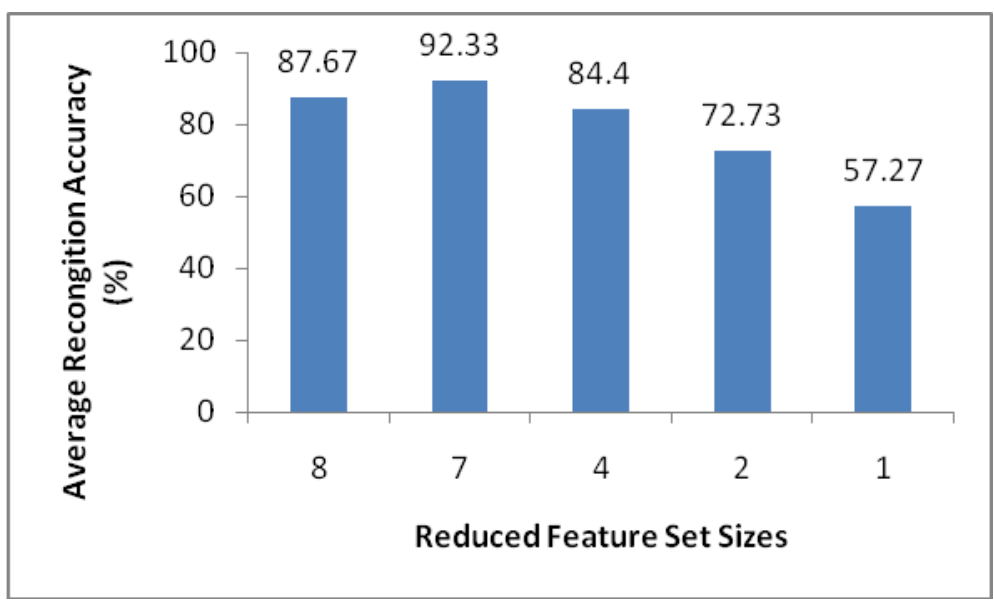

Figure 5. Recognition Accuracies of the HS Plane Reduced Feature Sets

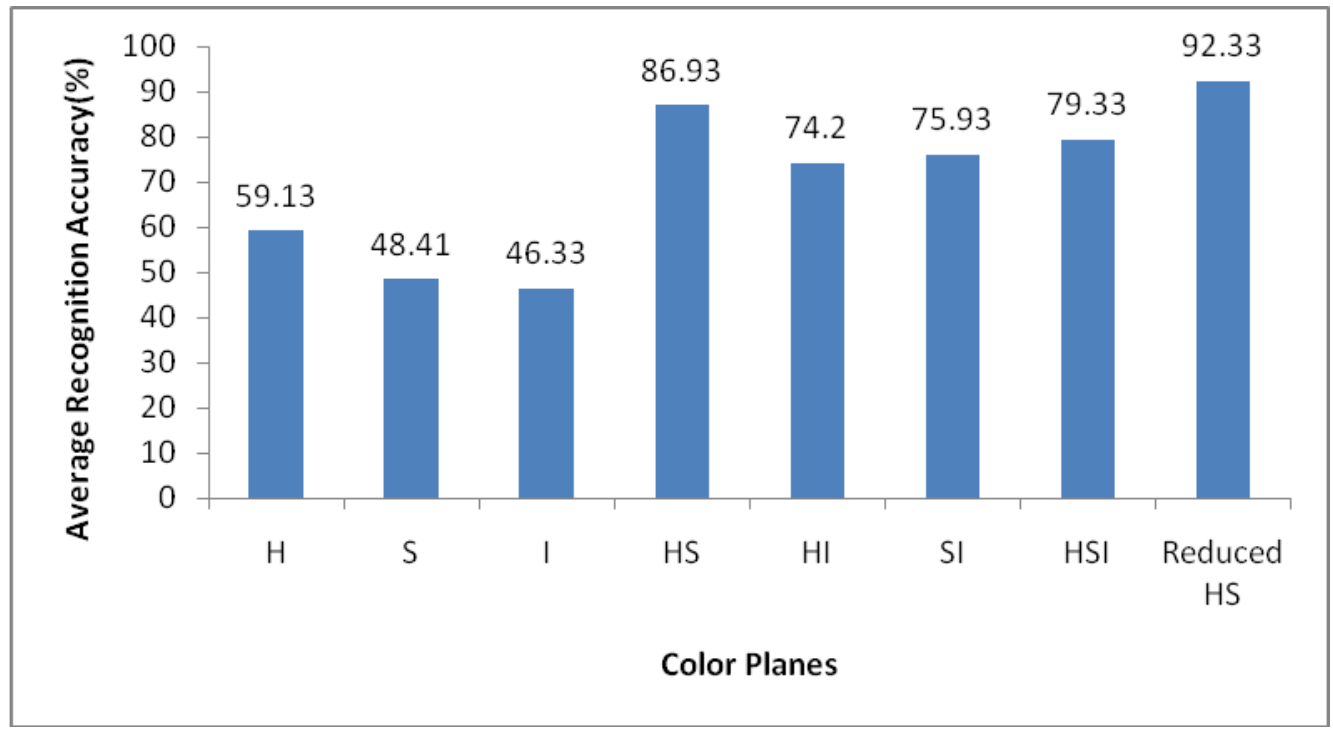

Figure 6. Behavior of HSI Color Texture Features for Variety Recognition of Bulk Paddy Image Samples

Table 6. Comparison of Proposed Method with the Literature

\begin{tabular}{|l|c|l|l|c|}
\hline \multicolumn{1}{|c|}{ Author } & $\begin{array}{c}\text { Paddy } \\
\text { Varieties }\end{array}$ & \multicolumn{1}{|c|}{ Sample Type } & \multicolumn{1}{|c|}{ Features } & $\begin{array}{c}\text { Accuracy } \\
(\%)\end{array}$ \\
\hline (Guzman J. D. et. al., 2008) & 5 & Singleton grain & 13 Morphological features & 70 \\
\hline (Pazoki A. R. et. al., 2014) & 5 & Singleton grain & $\begin{array}{l}24 \quad \begin{array}{l}\text { Color, } \\
\text { features }\end{array} \\
\text { flich Shape }\end{array}$ & 99.73 \\
\hline (Golpur I. et. al., 2014) & 5 & Bulk grains & 13 Color features & 96.66 \\
\hline Proposed method & 15 & Bulk grains & 7 Color texture features & 92.33 \\
\hline
\end{tabular}

\section{Conclusion}

The color texture features are used for recognition of 15 paddy varieties. The features are reduced based on the contribution made by an individual feature to the recognition accuracy. The recognition accuracy of $92.33 \%$ is obtained for reduced seven color texture features in combined HS plane. The proposed method has considered varieties three times more and number of features used is nearly half than the reported work. The results are 
encouraging. The number of features considered is half of the reported work. The work finds application in developing a machine vision system for agriculture produce market and developing multimedia applications in agriculture sciences.

\section{References}

[1] R. S. J. Mousavi, T. F. Akhlaghian and M. Kaveh, "Classification of rice varieties using optimal color and texture features and BP Neural networks", IEEE, (2014).

[2] A. R. Pazoki, F. Farokhi and Z. Pazoki, "Classification of Rice Grain Varieties using Two Artificial Neural Networks (MLP and Neuro-Fuzzy)”, The Journal of Animal \& Plant Sciences, vol. 24, no. 1, (2014), pp. 336-343.

[3] C. S. Silva and U. Sonnadara, "Classification of Rice Grains Using Neural Networks", Proceedings of Technical Sessions, vol. 29, (2013), pp. 9-14.

[4] A. Chaugule and S. N. Mali, "Evaluation of texture and shape features for classification of four paddy varieties", Journal of Engineering, Hindawi Publishing Corporation, Article ID 617263, (2014), pp. 8.

[5] R. S. J. Mousavi, K. Rezaee and K. Nasri, "A new method for identification of Iranian rice kernel varieties using optimal morphological features and an ensemble classifier by image processing", Majlesi Journal of Multimedia Processing, vol. 6, no. 2, (2012).

[6] A. Pourreza, H. Pourreza, M.-H. Abbaspour-Fard and H. Sadrnia, "Identification of nine Iranian wheat seed varieties by textural analysis with image processing", Computers and Electronics in Agriculture, vol. 83, (2012), pp. 102-108.

[7] D. G. Savakar, "Recognition And Classification Of Similar Looking Grain Images Using Artificial Neural Networks", Journal of Applied Computer Science and Mathematics, (2012).

[8] B. S. Anami and D. G. Savakar, "Recognition and Classification of Food Grains, Fruits and Flowers Using Machine Vision”, International Journal of Food Engineering, vol. 5, Issue 4, Article 14, (2009), pp. $1-25$.

[9] B. S. Anami, D. G. Savakar and V. S. Biradar, "Identification of multiple grain image samples from tray", International journal of food science \& technology, vol. 44, no. 12, (2009), pp. 2452-2458.

[10] J. D. Guzman and E. K. Peralta, "Classification of Philippine Rice Grains Using Machine Vision and Artificial Neural Networks", Iaald Afita WCCA World conference on Agricultural information and IT, (2008).

[11] B. S. Anami, D. G. Savakar, A. Makandar and P. H. Unki, "A neural network model for classification of bulk grain samples based on color and texture", Proceedings of International Conference on Cognition and Recognition, held at Mandya, India, (2005) December 22-23.

[12] X. Y. Huang, J. Li and S. Jiang, "Study on identification of rice varieties using computer vision", Journal of Jiangsu University, (2004).

[13] N. S. Visen, J. Paliwal, D. S. Jayas and N. D. G. White, "Image analysis of bulk grain samples using neural networks", Canadian Bio-systems Engineering, vol. 46, no. 7.11, (2004), pp. e7.

[14] J. Paliwal, M. S. Borhan and D. S. Jayas, "Classification of cereal grains using a flatbed scanner", Canadian Biosystems Engineering, vol. 46, (2004), pp. 3-1.

[15] R. M. Haralick, K. Shanmugam and H. Dinstein, "Textural features for image classification", Systems, Man and Cybernetics, IEEE Transactions on, vol. 6, (1973), pp. 610-621.

[16] S. A. Shearer and R. G. Holmes, "Plant identification using color co-occurrence matrices", Transactions of the ASAE, vol. 33, no. 6, (1990), pp. 2037-2044.

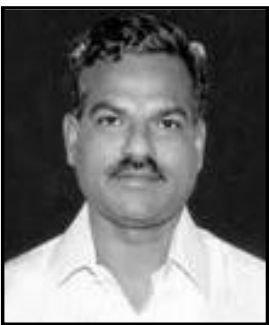

Basavaraj S. Anami, is currently the Principal of K. L. E. Institute of Technology, Hubli - 580030, Karnataka, India. He is one amongst the few who propagated Computer Education in North Karnataka. He has served as a Visiting Professor at Saginaw Valley State University, Michigan, USA during fall of 2006. Having 29 years of experience in teaching computer science and both at undergraduate and postgraduate levels, he is presently guiding five members for their Ph.D. He completed his Bachelor of Engineering in Electrical Stream during November 1981. Then he completed his M. Tech. in Computer Science at IIT Madras in March 1986. Later he received his Doctrine (Ph.D.) in Computer Science at University of 


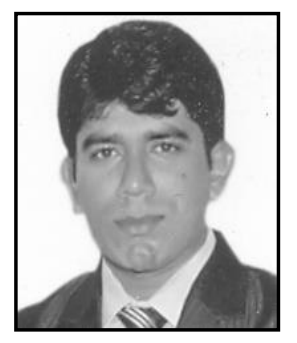

Mysore in January 2003. His areas of interest are Design and Development of Expert Systems, Parallel and Distributed AI, Neural Network based Expert Systems, Intelligent Computer Assisted Instructions, Machine Learning, Image Processing in Agriculture, Horticulture \& Food processing.

N. M. Naveen, is currently working as Assistant Professor in Department of Information Science and Engineering, K. L. E. Institute of Technology, Hubli - 580030, Karnataka, India. He completed his B.E. in Information Science and Engineering in July 2004 and M. Tech. in Networking and Internet Engineering in July 2006. He secured second university rank in M. Tech from VTU, Belgaum. He is currently pursuing $\mathrm{Ph} . \mathrm{D}$. in the area of image processing and pattern recognition from VTU, Belgaum.

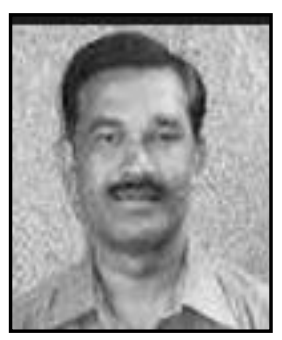

N. G. Hanamaratti, is currently working as Principal Scientist (Plant Breeding) in Rice Crop Improvement at University of Agricultural Sciences, Dharwad - 580005, India. He did research work in the field of Genetics and Plant Breeding and received 'JAWAHARLAL NEHRU ICAR AWARD 2009' for his Ph.D. thesis entitled "Identification of QTLs for physiological and productivity traits under drought stress and Stability analysis in upland rice (Oryza sativa L)". He has released 4 rice varieties for cultivation in Karnataka and published over 30 research papers in national and international journals. His areas of interest are characterizing traditional land races and developing rice varieties with drought tolerance and varieties with good nutritional quality. 